\title{
An ethicist's thoughts on the Termination of Pregnancy Bill debate in Malawi
}

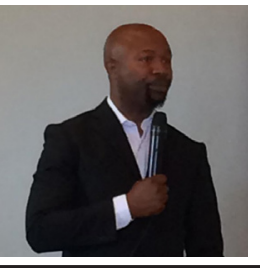

\section{Joseph Mfutso-Bengo}

Centre for Bioethics, School of Public Health and Family Medicine, College of Medicine, University of Malawi, Blantyre, Malawi

Correspondence: mfutsobengo@medcol.mw

Ethicists don't give you answers; rather they ask questions to help you think and reflect more before deciding, judging, and acting. So I would only like to ask some questions to both the proposing (pro-choice) and opposing (pro-life) groups. Both their arguments are sound, but I think these questions will help them think outside the box so that they may arrive at balanced, value- and evidence-based informed decisions.

To the proposing (pro-choice) group: will the new proposed changes in the abortion law be fair to all Malawians? I ask this question considering the fact that use of contraceptive methods, like condoms, is one of the ways to avoid unwanted pregnancies and is, in essence, a way of reducing unsafe abortions, yet due to various reasons (including socioeconomic factors) not all Malawians are able to access such methods (this is especially true in rural Malawi). Won't the same accessibility issues be encountered with regards to abortion services under the new proposed abortion law? What measures will the government put in place to ensure that safe abortion services are accessible to all?

To those opposing the amendment of the abortion law (pro-life group), especially religious people: are they trying to criminalise sin? I ask this question because I know that abortion is a sin from the Bible's standpoint, but no Bible verse allows us to criminalise sin. By the way, is it right for Christian leaders to be talking about criminalisation of abortion, or is it something outside their jurisdiction? Shouldn't they focus on preaching about repentance, forgiveness, and salvation? Should they focus on preaching about being holy so that the act of committing sexual sin should be avoided in the first place to avoid abortion? Many Malawian women, especially those in rural areas, have unwanted pregnancies due to inaccessibility of contraceptives; is it fair, under the current abortion law, to imprison these women and girls when they abort, when they were not exposed to contraceptives and information in the first place?

Lastly, to both the pro-life and pro-choice groups, I wish to express my understanding to their moral concerns. However, decision making by state and society should try to balance the rights of the mother, the life the unborn child, and the moral considerations of society. Can't we leave this issue of abortion in the hands of the individual woman's conscience to decide, rather than trying to decide on her behalf? The answer is No! Since this is affecting the third party-the unborn child-society has a right to say something, but that societal consideration ought to be balanced, fair, objective, and inclusive instead of exclusive. The interests of the mother, unborn child, and societal obligations all ought to be considered. I hope that by pondering over these questions holistically, we will see that the issue of abortion is not as simple as people think. It does indeed trouble our minds and conscience. 